\title{
COMES RIPACURCIAE Una intitulación diplomática de los Reyes de Aragón y su supervivencia
}

\author{
Felipe Mateu y Llopis
}

El objeto de estas páginas es corresponder a una invitación a colaborar en la Miscelánea dedicada a don Federico Udina Martorell, al dejar la dirección del Archivo de la Corona de Aragón por él dirigido hasta ahora; van limitadas por exigencia editorial, y tratan de sintetizar la historia de una intitulación diplomática que formó parte de las reales y quedó luego entre las más relevantes de la nobleza española.

\section{LO CAROLINGIO Y LO MUSULMÁN}

Partiendo de la magistral obra de don Ramón de Abadal y de Vinyals, Els Comtats de Pallars $i$ Ribagorça (J.E.I. 1955), quien resumió amplia bibliografía, entre la cual figuran Abad y Lasierra, Traggia, Valls Taberner y Villanueva, por citar solamente algunos de los que llenan sus ocho páginas de autores, se resumen aquí los antecedentes de esta institución que arranca de los tiempos carolingios y llega hasta los modernos.

El escenario lo constituyen las cuatro grandes cuencas fluviales: la del Segre, con su capitalidad en la Seu d'Urgell; la del Noguera Pallaresa, afluyente suyo, con Tremp como centro vital; la del Noguera Ribagorzana, también tributario del primero, con monasterios como Alaón y Lavaix en sus riberas; y la del Isábena que lleva al Esera, como éste al Cinca, con su sede episcopal en Roda, territorios repartidos, de oeste a este, en Ribagorza alta y baja, el Pallars, alto y medio, la Conca de Tremp y l'Urgellet y la Vall del Segre, cuya parte Sur es el Lleidatà, nombre que viene de la Iltirda ibérica y luego la Ilerda romana, Lérita 
árabe y Lérida romance, Lleyda o Lleida, comarcas que recorrí hace pocos años, personalmente'.

Siguiendo a Abadal, son fechas básicas las siguientes: en 781, la expedición del emir Abd-al-Rahman para dominar la zona pirenaica, con cuyo dominio se había alzado el Valí de Zaragoza al-Usain, según el Akhbar Madjmua; en 786-790, la Seu d'Urgell se hallaba fuera del dominio sarraceno; en 782 fue ajusticiado al-Husain por Abd-al-Rahman; los condes de Tolosa tenían una soberanía directa sobre el Pallars y la Ribagorza.

Sincrónicamente se dan aquí las genealogías o sucesiones condales y reales y la circulación monetaria coetánea; bajo el emirato de Córdoba, los Omeyyahs independientes se labraron con Abd-al-Rahman I (H.138-172: J.C. 755-788) dirhemes, los llamados por los cristianos sólidos o sólidos grossos, de plata y por esto argénteos o argenços y así lo hicieron sus sucesores hasta Abdallah (H.275-300.J.C. 882-912); e igualmente el dirhem durante el Califato, con el dinar.

De 807 es la refundación del monasterio de Gerri; los condes de Tolosa reedificaron Alaón y los obispos de UrgelI, Senterada; toda la Ribagorza había pertenecido, probablemente, a la diócesis de Lérida. En 841-845 circulan sólidos y sólidos argenteos en Ribagorza; en 849 Fredol conde de Tolosa y del Pallars-Ribagorza; en 859 el conde Ramón de Tolosa, in comitatu nostro palliarensi.

En 851 el emir Muhammad envía una expedición contra Barcelona, mandada por Musa, hijo de Musa, de la familia de los Beni Musa o Beni Lupo $^{2}$; en 859 Ramón I de Tolosa se intitula: Raimundus divina anuente gracia comis et marchio; en 871, Bernardus, gratia Dei comis, dux atque marchio; era de Tolosa; en 884-920, Ramón I, conde de Pallars-Ribagorza: Bernardus comes fuit Riparcuciensis cum adhuc totam fere Hispaniam tenerent mauri: cum Ato episcopus frater eius expulasset mauros de Palliarensis terra, ille expulit de Ripacurciensi (Chronicon de Dominicus).

1 ABADAL. Els comtats, cita que el P. PAsqual dejo inéditas unas Memorias de los Condes de Ribagorza, p. 6, en sus Sacrae antiquitatis Cataloniae Monumenta, Ms. 729 de la Biblioteca de Catalunya; el P. LLoBet y Mas que escribió Erección del Reyno de Pamplona. Árbol genealógico serie y sucesión de sus primeros reyes y Genealogía de los Condes y Marqueses de Pallars y Ribagorza, justificado todo con Diplomas y Autores coetáneos: I. Precedentes época visigótica. II. Reino de Pamplona. III. Pallars y Ribagorza: Ms. 426 de la Biblioteca de Catalunya, docs, de 782 a 1303; amplia información en Abadal, L, 6: docs. de los monasterios de Gerri, Tabernoles, Lavaix, San Juan de la Peña, Alaón, San Victorian, Roda, La Serós, Meyá, Jaca, Ainsa y Alquezar; Llobet Mas sucedió a Abad y Lasierra en el priorato de Meyá en 1785.

En 1946 di en Analecta Sacra Tarraconensia un conspectus «De la Tarraconense visigoda a la Marca hispánica carolingias en 122 páginas y unos grabados, que valen como antecedente al tema actual.

2 J.M. MHL.Ás VAL.LICROSA, Aspectos de la dominación árabe en la región ilerdense, IEI, 1948. 
En 868,871 y 920 es frecuente la palabra pagus, la tierra, que da origen a país; en 872 es asesinado el conde Bernardo de Ribagorza. En 883, Ismail fortifica su ciudad de Lérida, contra el conde de Barcelona Guifré; en 884, Ramón, conde independiente de quien descienden las dinastías de Pallars y Ribagorza. En 888, erección del obispado de Roda, independiente del de Urgel, el cual pertenecía desde el Conde Ramón. En 989, en Lavaix / sou, x argenços, xxi argenços; $x$ argenços, en Alaón. En 890, Musa y Mustarrif, hijos de Ismail ben Musa, de Lérida, contra Muhammad al-Tawil de Huesca que les disputaba la Barbatania, o sea, la región de Barbastro y la Litera en la Ribagorza, Muhammad al-Tawil se apoderó de la Barbatania y entró en Lérida.

En 901, x.m. solidos, Alaón: 902 xii argenços, Alaón. En 904, invasión del Pallars por Lo ibn Muhammad, wazir de Lérida. En 909, iii solidatas (Alaón). En 915-954 Mirón, hijo de Ramón L. En 915, v. solidos et iiï argenteos (Alaón). En 916-950, Bernardo, hijo de Ramón I, conde de Ribagorza. En 918, Isarn, conde de Pallars, primo de Sancho Garcés I, de Navarra (905-925). En 923, ccc. solidos (Gerri). En 927, iii solidos (Alaón). En 930-936, xxxx et v. solidatas (Lavaix). En 939, ii solidos et iiii argenteos (Isabena). En 948, solidos. cccc. En 949, Willelmus gratia Dei comes (Gerri). En 950, Unifredus gratia Dei Comes (Gerri).

En 904, Lupo lucha contra los cristianos de la región de Pallars. En 907, Muhammad al-Tawil se apodera de Monzón y entra en Lérida: el rescate de cautivos en Pallars «le valió 13.000 monedas de oro» (Millás).

En 947, Guillermus comis (Lavaix). En 947, Isarnus comes et uxor mea Adalisis comitissa (Gerri). En 954, Ego Miro comis (Alaón). En 956-960, Raimundus Dei gratia comes; es Ramón II, conde de Ribagorza, En 958, Raimundus, divina gratia comes et marchio (Lavaix). En 960, Raymundus comes et Gassindi comitissa (Carbonell, Anales del Condado de Ribagorza). En 960, vc. solidos ad argenteis (Traggia).

En 960-979: Unifredo, Hunifiredus, chomes, de Ribagorza (Alaón); xii. argenteos. En 966-990, Arnaldus divina gracia comes et marchio (Lavaix). vi. solidos (Alaón). En 972, García Fernández, conde de Castilla (970-995), casa con Ava, o Aba, hija de Ramón II (956-960). En 975, Tota o Toda, casada en 1006-1007 con el conde Sunyer, de Pallars (966-1010-1011). En 972, Unifredus comite et coniux mea Sancia. En 973, Hunifredus gratia Dei comis dux atque marchio (Alaón). En 975, Hunifredus comes et matrem suam Arsindis chomitissa. En 979, Ego Hunifredus gratia Dei comis et ego Sanciam coniugem suam (Alaón) Ramón II casado con Garsendis, hija del conde de Fesenzac quien dio su hija Ava al conde García Fernández, citado.

En 988-990, Ego Arnaldus Dei gratia comis (Lavaix). En 990, Ego Garsindis chomitissa et ego Isarnus gratia Dei comis sive germana mea Tita chomitissa (Abad y Lasierra). En 996, in comitatu Ripacurciensi (Serrano Sanz); en 994-1000, García Sánchez II el Trémulo, rey de Pam- 
plona. En 980-990, redacción de las Genealogías rotenses ${ }^{3}$. Aguinaliu estaba bajo la autoridad del wisir de Zaragoza en 987; se citan solidos argenteos.XX.

De Ramón I y Ginigenta nacieron Isarn (904-948?) y Llop (923-948?), de quienes derivó la casa condal de Pallars; y del hijo Bernat-Unifred (916-950), casado con Galindona, hija de Galindo Aznar II de Aragón; y del otro hijo de Ramón I, Mirón, derivó la casa condal de Ribagorza cuyos condes fueron: Ramón II (956-990); Unifredo (964-979); Isarn (964-1003); Arnau (964-988-90); Ava, casada con el conde de Castilla, García Fernández, (970-995); Toda (975-1008) casada con el conde Sunyer de Ribagorza, en 1006-1007; el conde murió en 1011.

\section{ENTRE LAS DOS CORONAS}

En 1000-1035, Sancho III Garcés, el Mayor, «descendiente de doña Dadildis de Pallars y marido de doña Munia, que era nieta de la condesa ribagorzana doña Ava» intervino ante la «anarquía y dificultades que sufrieron los condados de Sobrarbe y Ribagorza, invadiéndolos. En 10161019 (Ubieto D.H.E.3,578), Ego Sancius rex tenens culmen potestatis in Aragone et in Pampilona et in Sobrarbi et Ribagorza et in Nagera et in Castella et in Alava. Sancho III al morir dejo heredero de Sobrarbe y Ribagorza a su hijo Gonzalo; asesinado éste, ambos condados quedaron incorporados a la corona del rex Aragonensium.

En 1065, Sancho Ramírez impugna Barbastro (1063-1094). En 1068, Berenguer Ramón I y Almodis, llevan a cabo una cruzada contra Barbastro, pero su toma no llegó hasta 1101 por Pedro I (1034-1104); desde la conquista de esta ciudad los obispos de Roda residían en ella y después de 1149 lo hicieron en Lérida.

Sancho Ramírez (1063-1064) Sancius Ranimiriz, tex aragonensium et pampilonensium, conservó aquellos dominios que mantuvo su hijo Pedro I Sánchez (1094-1104); Ego Petrus Sangis aragonensium et pampilonensium rex en su intitulación y en las cláusulas de soberanía. Petrus Sangis Dei gracia regnante me in Aragone et in Pampilona et in Superarbi et in Ripacurcia, esto es, se hallaban sobre la misma cabeza las dos coronas, la de Aragón y la de Pamplona, que sería Navarra.

En las cláusulas de soberanía, el primer rey aragonés se menciona rex in Aragone como el pamplonés, rex in Pampilona; aquí entra una ciudad, allá una

${ }^{3}$ Serrano Sanz. Noticias. Lacarra. Textos navarros del Códice de Roda (EEMCAD). Sobre el período 1018-1025-1035. FERran Sol.Devila, Historia de Catalunya (Barcelona. Alpha, 1934, p. 93; utiliza a VALS TABERNER, «Els origens dels comtats de Pallars i Ribagorças, EUC, 1915-1916. 
regio que toma su nombre de un río, el Aragón; como la ciudad da un gentilicio, pampilonensium, el río dio aragonensium; así Sancho Ramírez rex aragonensium et pampilonensium fue rey de los primeros, desde 8-V-1063, y de los segundos desde 1076. Los aragonenses tuvieron también una ciudad cabeza, la ibérica Iaca o Jaca, de donde iaccensium o iaccensis, como se llamó la moneda de los aragonensium. Ego Sancius Ranimi era la forma patronímica; gracia Dei aragonsium et pampilonensium rex, era la gentilicia de Sancho Ramírez (1063-1094), quien regnante in Aragone et in Pampilona acuñaría con el nombre de la ciudad y luego del río: Sancius rex Iaca y Aragón.

Al comenzar el milenio la región pirenaica aparece dividida entre el reino de Navarra, el naciente de Aragón (1035) y los condados que reconocieron como cabeza el de Barcelona; la raya divisoria dejaba el país del Ebro en poder de la Beni Hud de Zaragoza, cuyo reino rehacía el convento jurídico romano cesaraugustano y abarcaba parte del cartaginense. Antes de 1085, se lleva a cabo la conquista de Toledo; los reinos cristianos tenían una configuración horizontal, como los conventos romanos; así, mientras la zona libre en el norte, comprendía los tres conventos de la Gallaecia: el lucense, el bracarense y el asturicense, más el cluniense, llegando a la cordillera carpetovetónica, en la zona ocupada se repartían los conventos de la Lusitania y parte de la Cartaginense, los reinos moros de Toledo, Badajoz y Sevilla, y las configuraciones horizontales correspondientes a las cuencas del Tajo, del Guadiana y del Guadalquivir.

En la frontera superior se había constituido un poderoso estado a base del Ebro, pues en 941 caý Tarragona y en 947 Lérida y Balaguer, allí una familia de origen godo, los Benicasi, se habían hecho rebeldes en pleno siglo x. Desde 1017 una dinastía particularista inició con Mondir aquel núcleo en el que Suleiman ben Hud (1039), gobernador de Lérida, crearía, a su vez, la dinastía de Zaragoza, estableciendo en sus hijos cuatro pequeños reinos: Zaragoza con Abu Chafa Ahmed; Lérida con Abuhomar Yusuf Almudafar; Calatayud con Mohamed Abidoddaula; y Tudela con Alhachib Mondir; los cuales rehacían territorios de ilergetes y edetanos en gran parte y aquel convento cesaraugustano, por poco tiempo, puesto que ZaragozaAhmed aspiraba a la unidad que rehizo y superó en 1061, completando el curso del Ebro al ganar Tortosa y aspirando a integrar la primitiva Tarraconense - la Hispania Citerior - al lograr Denia; con lo que en el último tercio del siglo XI reapareció el país propiamente ibérico, desde Pamplona, Huesca y Lérida, por la divisoria de aguas, Soria, Guadalajara, Teruel, hasta Valencia y Alicante, la España mediterránea mora que se mantenía por sus tributos, las parias, ante la presión de Fernando I y Alfonso VI de LeónCastilla (1037-1065 y 1072-1109).

El imperio almorávide en España se extendió por el sur y el levante peninsular cayendo Tarifa (1090); Córdoba (1091); Carmona y Sevilla (1091); Murcia, Xátiva, Denia y Valencia (1092); y Fraga, en territorio del 
Ebro (1093). Fueron soberanos almorávides: Abubequer ben Omar (10561087), con residencia en Segilmesa; Ibrahim ben Abu Bequer, en África y Al-Andalus, Yusuf ben Texufin (1087-1106), que poseía Ceuta, Fez, Segilmesa, Agmat, Xátiva, valle de Aspe a Santa Cristina, y de aquí por el río Aragón a Canfranc y Jaca, desde donde hacia el oeste, pasando el río hasta Sangüesa y de aquí a Monreal y Eunate a unirse con el paso desde Roncesvalles y Pamplona a Puente de la Reina.

Cuando Ahmed hubo de partir su reino, creó dos centros políticos: uno interior en Zaragoza y otro marítimo en Tortosa y Denia, con Mondir; pero el escenario zaragozano iríase reduciendo por conquistas cristianas. En 1089. Monzón, ganado por Sancho Ramírez (1063-1094); y Huesca (1096), por Pedro I (1094-1104), después de Alcoraz; cuando murió Ahmed (1110) no tardó en caer Zaragoza (1118) bajo Alfonso el Batallador (1104-1134); el Ebro musulmán sin Zaragoza, caería bajo Alfonso II (1162-1196); y el condado de Barcelona con Ramón Berenguer IV (1131-1162) se uniría personalmente, con el viejo reino de Aragón; en el sur se había mantenido el particularismo territorial hasta la invasión almoravide; Almería se hallaba bajo Almotasim; Córdoba, con los Benichamar; Murcia con los Bentahir; Albarracín, siempre aislacionista, con un gran fondo mozárabe; Santa María de Abenracín, y Alpunte, Elpont o Alpont, con sus propios reyes, mosaico político anterior al 1100 .

Al romperse la unidad del Califato renació el particularismo hispano. con los reinos de taifas, a cuya diversidad puso fin el imperio almorávide, que hubo de caer también en la península en 1146, con nuevas taifas, hasta que lo almohade (1129-1268) quiso rehacer lo que restaba de Al-Andalus, cada vez más reducido por las conquistas de Castilla y Aragón, quedando dos reinos: Murcia (1223-1258) y Granada, más longevo (1231-1492).

Ramón Berenguer IV ganó Tortosa en 1148 y Lérida en 1149; en 1161 recibía parias del rey Lobo de Valencia y Murcia, causa del curso de valores musulmanes en los condados dependientes del de Barcelona, tales los morabatines ayadinos y lopinos, de Lopo o Lobo.

El P. Josep Poch ha publicado en Revista Catalunya (1980, núm. 222) un esquema topográfico, según la tesis de Mn. Antoni Griera, en el que se anota como territorio original del Condado de Ribargoza: Les Pauls, Roda, Lasquarre, Laguarres, Benavarre, Tolva, del siglo xI; Pont de Suert, Sopeira y Areny, los tres áltimos en la orilla izquierda del Ribagorzana. De las conquistas de Urgell y Barcelona: Purrol, Pilçà, Calassanç. Peralta de la Sal, Tamarit, Calladrons, Tremp, Ager y Balaguer; como conquistas aragonesas: Benasque, Barbastro, Estadella, Monzón, Binéfar y Fraga —estas cuatro a la izquierda del Cinca,

Repartidos los territorios de la corona navarra entre los hijos de Sancho el Mayor III (1000-1032), García Sánchez III —el de Nájera (10351054) - quedó con la Navarra estricta y el señorío del resto del país vasco; 
Fernando, con Castilla; Ramiro, con Aragón; y Gonzalo, con Sobrarbe y Ribagorza. Asesinado Gonzalo los sobrarbinos y ribagorzanos aclamaron a Ramiro I de Aragón (1035-1063), quedando por convenio entre los tres hermanos Sobrarbe y Ribagorza incorporados a este reino en 1044.

García III Sánchez (1035-1054) fundó el monasterio de Santa María de Nájera, de donde se le da tal designación, y en aquella plaza acuñó moneda y desde allí cercó Calahorra en 1045, hasta ganarla. Sucedióle Sancho Garcés IV, el de Peñalén (1054-1076), en Navarra; y a Ramiro I, en Aragón, su hijo Sancho Ramírez I (1063-1094).

En Castilla, a Fernando I Sánchez (1037-1065) sucedióle Sancho II (1065-1072), que invadió las tierras del rey de Pamplona - Sancho Garcés IV, el de Peñalén (1054-1076) - y asesinado éste, Alfonso VI de Castilla (1072-1109) cruzó el Ebro e invadió Navarra, pero el rey de Aragón, Sancho Ramírez I (1063-1094) avanzó también y llegó a Pamplona, inclinándose por él los navarros y titulándose rex pampilonensium et aragonensium; Alfonso VI de León-Castilla se quedó con el dominio de la Rioja, las plazas de Najera y Calahorra y parte de Vizcaya; Sobrarbe y Ribagorza, más alejados de las zonas polémicas, quedaron de Aragón.

La toma de Barbastro según la «Crònica d'Alaó renovada», de acuerdo con el Cartoral se halla en este texto así: modo vocare convenit eos Barbastrinos quia jam Dei gratia capta Barbastra et a Christianis possesa, dignum est ut nuncupentur sicut antiquitus, quia desierant esse episcopi in Hilerda. (Abadal, I, 25). Más adelante: Et post istum Salomon Rivipullensis monachus episcopus fuit, qui quantum potuit melioravit episcopatum cum Ranimiro venerabili rege: cui prefatus rex Rotam dedit per hereditatem jure perpetuo.

Y sigue: Quo ejecto ab episcopatu accusacione suorum, electus est probus Raimundus Dalmacii, qui astucia et sanguine et precibus a religioso domno Sancio rege, effecit ex paupere episcopatu mediocrem, et possuit sedem suam in Rota et vocatus est primus Rotensis episcopus (ante eum vero) episcopi Rippacurcenses vocabantur.

Prosigue: Post cujus obitum Lupus fuit sed dimisit episcopatum, nec diu tenere voluit. Post quem electus est dominus Poncius, qui Barbastrensis episcopus dictus est, et ipse hoc impetravit a duobus apostolicis Urbano et Paschasio et a domino Petro rege Aragonensi. Y a seguida: Huic successit bone memorie et vite venerabilis sanctus Raimundus, post gloriosam mortem cujus Stephanus electus est. Cui nolenti suscipere episcopalem consecracionem, finita tamen eleccione, successit Petrus Guillelmi, monacus Sancti Victoriani, qui mortus est gladio in obsidione Fraga cum inumerabili multitudine Christianorum pereuncium in bello.

En septiembre de 1976 tuve oportunidad, gracias a Mn. Jesús Tarragona, delegado de Bellas Artes en la dí́cesis ilerdense, de visitar la iglesia de Alaón, que se hallaba en plena labor restauradora, y al bajar a la cripta 
observamos un letrero, encalado, que previamente descubierto dice así, tras el crismon trinitario, esto es, P,X. cruz, S y laterales alfa y omega XIII KL DCBR RAIMUNDUS BARBASTRENSIS EPC CONSECRAVIT HOC ALTARE IN HONORE SCORUM PETRI ET PAULI y otro cercano que reza así: CORPRA SACTORUM HYRENEI ET ALBINI; la primera leyenda, en letra capital, en vermellón; la segunda, en mezcla de minúscula y uncial. El lugar de tradición clásica: una inscripción romana MAXIMO LABIENO VALERIO inserta en el muro exterior, a ras de tierra.

\section{EL CONDADO EN EL REINO DE ARAGÓN}

1104-1134, Alfonso I el Batallador, rey de Aragón, se intitulo rex ribagorcensium. En 1117, centum.$X L$. solidos grossos de ripacurcia; también .XX. sollos (abreviatura de solidos) grossos de ripacorza $a^{4}$. Alfonso I Sánchez (1104-1134) tomó Ejea (1110), Zaragoza (1118), derrotó a los almorávides en Cutanda (1120), hizo una expedición a Valencia (1185), fue derrotada en Fraga el llamado Batallador, y entró en 1111 en Toledo. En 1126, coronado ya emperador el rey de Castilla-León, Alfonso VII, Alfonso I aun poseía Burgos, Carrión, Vilafranca de Montes de Oca y Castrojeriz. En 1129 decía regnante me Dei gracia in Castella et Aragone sive in Pampilona in Superarbi et in Ripacurça y antes, en 1128 , regnante me Dei gracia in Aragone, Navarra in Superarbi et in Ripacurcia et in Castella et in Vizchaia et in Alava, según documento de la catedral de Pamplona. En 1131 se intitulaba Ego Adefonsus aragonensium et Pampilonensium sive ribagornensium rex; fue la expresión del mayor reconocimiento del antiguo condado de Ribagorza, pues que de él no se consignaba comes sino rex.

Bajo Ramiro II (1134-1137), separados Aragón y Navarra por la negativa de los aragoneses a entregar el reino a los Templarios y Hospitalarios, como disponía el testamento de Alfonso I (1131), en la intitulación del nuevo monarca se pasó de rex aragonensium a rex aragonensis, en su dominio quedaron Sobrarbe y Ribagorza como territorios integrados en su reino. El de Ribagorza, como el de Pallars, dependiente del marquesado de Tolosa e independiente después, había pasado entre los años 1018-1025 a manos de Sancho Garcés III, el Grande, rey de Navarra (1000-1035), descendiente de una hermana del conde Ramón I de Pallars y Ribagorza

${ }^{4}$ Boter, Les mon. cat. I p. 67-68; donde dice de la moneda de Ribagorza ade la qual que sapiguem no se n' ha trobat caps, con referencia a CARRERAS CANDI *Monedes de l'Urgellets, Bol. Soc. Artística-Arqueológica de Barcelona (1906), añadiendo que, aungue la moneda de Ribagorza hubiera corrido en el condado de Pallars «no pot considerar-se propia del comtat de Pallars (p. 165). En Ribagorza corrian los dirhemes califales y taifales; el rey de Zaragoza, Ahmed Almostain (H. 476-503) (J.C. 1083-1102) acuñ6 dirhemes. 
casada con el rey García Jiménez. Hacia 1035, a la muerte de Sancho Garcés, quedó independiente de nuevo, quien lo dejó a su hijo Gonzalo y volvió al rey de Aragón para no separarse más.

El momento histórico es el del desarrollo monetario condal, antes que el de Alfonso VI de Castilla (1072-1109) y en pleno triunfo del románico en Cataluña, desde los siglos x y XI hasta los albores del XII; en 1110 se comenzaba la catedral de Urgel por san Ermengol: cruz latina, tres naves y cinco ábsides (1175); san Juan de las Abadesas era dedicada en 1150; antes san Pedro de Galligans, iglesia fortaleza, en 1137.

\section{JAIME II (1291-1327)}

El 18 de febrero de 1310 llegó a Valencia Jaime II después de haber levantado el sitio de Almería; al haber de satisfacer estipendios a asalariados del ejército lo hubo de hacer en moneda jaquesa por no disponer de valenciana; el 3 de abril de aquel año ordenó que se admitiese la moneda jaquesa a razón de doce dineros de ésta por 18 valencianos.

Durante el reinado de Jaime II se intento sustituir el gobemador general de Cataluña por cuatro sobrejunteros, como sucedía en Aragón, donde representaban al monarca; aquéllos radicaban en Barcelona, Gerona, Lérida y Tortosa. La actuación del infante don Pedro se halla enmarcada en este cuadro cronológico. En 1312, la ciudad de Valencia usa el sello municipal representativo de una ciudad sobre el río, cuyo emblema son dos ondas: la ciudad compuesta por una muralla de cuatro torres cuadradas, con tres merlones cada una, una central redonda que representa el cimborio de la catedral, sobre la cual hay una cruz que viene a estar en el mismo eje de la cruz inicial de la leyenda sigilar $S$ (igillum) CVRIE ET CONCILII VALENCIE.

En las cortes de 24 de octubre de 1329 celebradas en la catedral de Valencia se publicaron los nuevos fueros, hallándose presentes los hermanos del rey, infantes don Pedro y don Ramón Berenguer, además de los maestres del Hospital, Calatrava y Montesa, el comandador de Montalbán, al abad de Valldigna, y los nobles Sarriá, Bellpuig, Centelles, Montcada, Próxita y Lauria o Lluria?.

5 J.E. Martinez Ferrando, Jaime II de Aragón, II, p. 101, doc, 148 Manuel Dualde Serrano, «Tres episodios zaragozanos de la lucha entre Pere el del Punyalet y la Unión aragonesa relatados por el monarca a su tío Pedro, Conde de Ribagorzas, Est. Ed. Media Corona de Aragón, II, p. 294. Don Pedro de Aragón, cuarto hijo de Jaime II de Aragón y Blanca de Anjou, n. 1305; en 1322 recibió el título de conde de Ribagorza y señor de Entenza. Referencias a Zurrta, Anales, VII, c. 40. Véase también Alfonso Marfa de Barcelona, «EI Infante fray Pedro de Aragons, Estudios Franciscanos (1913), L. XI, XII, XIII. 


\section{LA NUEVA «CREACIÓ DEL COMTAT»: EL. INFANTE DON PEDRO DE ARAGÓN}

La creación y donación del condado de Ribagorza fue hecha por Jaime II de Aragón en 13 kalendas junias, el 20 de mayo, día de la Ascensión, de 1322 en la catedral de Lérida, a favor de su hijo Pedro. El Translat de la donacio e creacio del comtat de Ribagorca se halla en el registro 632 del Archivo del Reino de Valencia, cuyo tenor se reproduce aquí, íntegramente, pero dándolo por los períodos de su redacción literaria, con la glosa oportuna.

El rey expresa la motívación del acto: In nomine domini nostri Thesu xristi amen. Nos Jacobus dei gracia Rex aragonum, Valencie, Sardinie et Corsice ac comes Barchinone: Affectantes dum promitente altissimo vita fruimur corporali sic de bonis nostris inter filios nostros nobis celesti benediccione concessos, disponere ut singuli ordinacione nostra contenti sibi ad invicem caritatem dileccionis fraterne custodiant et conservent possit inter eos alicuius dissensionis materia quod avertat altissimus pullurarem.

Concede el condado a su hijo Pedro por paterno favor: Idcirco volentes nos inclitum karissimum et graciosum nobisque amabilem filium meum infantem Petrum paterno et regio favore prosequi et ad Comitalem dignitatem honorabilem acollere insignare ac eciam sublimare, comperto ex scriptis antiquis terram Rippacurcie Comitatum fore et a nostris predecessoribus Regibusque aragonum illustribus memorie recolende fuisse, terram ipsam Comitatum in scriptis publicis nominatam.

El monarca conoce la documentación antigua por la que las tierras que pasa a describir, integraron el condado: Per nos et nostros presentes et futuros, gratis ex certa sciencia ac spontanea voluntate damus et concedimus titulo pure et irrevocabilis donacionis inter vivos vobis dicto infanti Petro presenti et recipiente a nobis iam emancipato, vestrisque legitimis successoribus in perpetuum totum Comitatum nostrum Rippacurcie supradictum cum omnibus et singulisCastris locis nostris que ad manus nostras tenemus et quem habemus et habere debemus.

La donación incluye: Infra dictum Comitatum Rippacurcie et alia eciam omnia et singula Castra et loca que, que barones, Milites et aliquicumque homines ibi tenent vel tenere debent pro nobis ad feudum vel alio quoquomodo in quantum videlicet ad nos vel iura nostra possint vel debeant pertinere in dicto Comitatum infra terminos subdistinctos, volentes et declarantes quo Castrum et locus de Entença situm in Rippacurcia quod ad nos pervenit ex donacione nobis facta per nobilem quondam Guillem de Entença intelligatur et comprehendatur in presenti donacione nostra.

El señorío de Entenza quedo, pues, incluido en el título condal: Guillem de Entenza había sostenido guerram con Guillermo de Anglesola por la 
cual Jaime II, en Valencia a 4 de febrero de 1313-1314 pidió a éste que no causara daños en el edificio que el soberano construía en el Coll de Balaguer, por ser morada suya en sus viajes.

A continuación se fijaban los límites del condado: Terminamus autem seu limitamus dictum Comitatum a terminis Montissoni et Castellanie eiusdem exclusive deinde insequendo flumine Sinche sicut ascendit usque in directum talliate de Castro et sicut ascendit serra usque serram de Paniello aquis vertentibus usque partem Rippacurcie, villa et termini dicti loci de Paniello remanentibus infra limitationes dicti Comitatu et deinde in sursum sicut serra ascendit usque ad troncedo aquis vertentibus, usque partem Rippacurcie dicto loco de Troncedo excluso cum sit de superarbio, et sic protenditur serra usque ad foradada, que est inter Rippacurcia et Superarbium et deinde sicut insequitur portus usque ad portum de lisac et sicut aque vertunt usque Rippacurciem est de Rippacurcia et de dicto porto de lisac, aquis vertentibus usque Rippacurciam.

Excluido Troncedo por ser de Sobrarbe, añade Lisaz cum termino de Benasch, et eius honoris, usque ad portum de benasch, qui afrontat cum Vasconia sicut portus sequntur aquis vertentibus, usque partem Rippacurcie qui afrontat cum Vasconia, et in valle nostra arani, exclusive, usque ad portum de Cenet qui afrontat cum dita valle arani.

Salvado el Valle de Aran, que era de la corona, prosigue: et deinde usque ad flumen Nogarie Rippacursane et sicut descendit inferius ipsum fumen Nogarie Rippacursane, versus partem Rippacurcie, usque in directum de Montesicco, et deinde usque ad terminos exclusive locorum Tamariti et sancti Stephani de litera et postea ad terminos Montissoni et Castellanie eiusdem ut predicitur exclusive, usque ad dictum fluminem Sinche.

El Cinca era fronterizo; y añadía: Itaque volumus statuimus et ordinamus quod vos et vestri intitulemini perpetuo Comites Riparcurcie et sitis dignitate et honoribus comitalibus plenarie insigniti.

A seguida: Itaque Comitatum Rippacurcie prout infra dictas limitaciones includitur cum baronibus militibus feudaris, sive castellanis, feudis et cum omnibus hominibus et feminis cuiuscumque condicionis seu legis existant, ibidem habitantibus et habitaturis, et cum omnibus dominicaturis mansis honoribus et possessionibus quibuscumque, et cum terris omnibus heremis et popularis, et cum montibus et planis garrigis cumbis sive vallibus, et cum fluvis rivis sive fontibus ademprivis tallis et collectis subsidiis et questis monetaticio et cum iusticiis et calonis districtibus placitis firmamentis et stacamentis et cum banis et faticis et cum mero atque mixto imperio, et cum omnibus dominiis seu donacionibus potestatibus quibuscumque et jurisdictionibus, lezdis, passagüs, carnalagiis et solito guidatico bestiariis et mensuraticis, pensis hostibus exercitibus et cavalcatis et redempcionibus eorum et cum pace et guerra et cum omnibus 
reditibus exitibus fructibus proventibus obventionibus invencionibus sive trobis decimis quartis et tercis et cum omnibus pertinenciis et adiacentiis predicti Comitatus et predictorum omnium et singulorum que vobis damus et cum omnibus aliis et singulis que nos ibi habemus vel habere debemus aut possumus quibuscumque modis iuribus racionibus vel causis prout melius nostri antecessores habuerunt.

La transferencia de los derechos del rey era completa: la host, la cavalcada, el monetaticum, pesos y medidas y cuanto se ha consignado, como base económica, administrativa del comitatus; y se concedía in feudum honoratum al infante don Pedro en esta forma: et nos premissa omnia habemus et habere debemus et possumus damus et concedimus vobis dicto infanti Petro filio nostro et successoribus vestris imperpetuum. Ita tamen quod predicta omnia et singula habeatis teneatis et possideatis vos et vestri perpetuo sub hiis condicione retencione modo et forma, quod dictum Comitatum cum omnibus et singulis supradictis vos et vestri teneatis in feudum honoratum absque alioque servicio secumdum usaticos Barchinone et consuetudines Catalonie imperpetuum pro nobis et heredi nostro universali qui rex fuerit Aragonum et successoribus eius et in ipso Regno, et teneamini vos et vestri pro dictis Comitatu et feudo prestare et facere homagium nobis et nostris teneamini et vos et vestri irati et paccati dare nobis et nostris potestate loco et vice totius Comitatus et omnium et singulorum Castrorum et fortaliciorum eiusdem tantum modum de Castris et locis de Muntanyana de Areny de Stopanyano de Viacamp de Falç et de Fontova et terminis eorum secumdum predictos usaticos Barchinone et consuetudinis Catalonie.

Añadía: quocumque et quotienscumque eam vel eas duxerimus requirendas, nec de aliis Castris seu fortaliciis vel locis dicti Comitatus, preterquam de supraproxime expressis sex casis et locis nobis vel nostris vos vel vestri dare teneamini potestatem, declaramus quod vos vel vestri de aliis Castris seu locis dicti Comitatus vel terminis eorum pretextu vel causa predictarum potestatis vel potestatum exire non teneamini set tamen remaneant et sint feudum sub forma superius (expressa) comprensa.

Se imponia al conde infante acudir a las Cortes generales de Aragón: Eciam teneamini vos et vestri venire ad curias generales Aragonie et interesse in eis quantis et quociens per nos vel successores nostros mandatum vel requisicionem receperitis, super eo et eciam alia facere et complere qui alii tenentes pro nobis in Catalonia feuda honoraria facere tenentur et debent.

Se ordenaba también el curso de la moneda jaquesa: Sane, quia per predecessores nostros et nos promisum est atque iuratum universitati Regni aragonie quod monete iaccensium in omni firmitate, secundum quod nunc est in perpetuum currat publice atque duret et quod destruhi non valeat nec mutari aut minui vel augeri, quodque currat ubi currit aut 
currere consuevit. Propterea huiusmodi promissionem et iuramentum nos non deceat transcendere vel mutare per ea firmiter tenere et facere perpetho inviolabiliter observari.

Asegurado el curso de la moneda jaquesa en el condado ribagorzano se prohibía que la misma u otra cualquiera pudiese ser hecha en el mismo: statuimus et ordinamus premissis de causis quod dicta moneta Jaccensis que actenus in Rippacurcia currere consuevat vel illa moneta que generaliter curreret in Regno aragonie et non alia currat perpetuis temporibus in dicto Comitatu Rippacurcie, et universis et singulis locis eius inibentes vobis et vestris perpetuo nec ullo unquam tempore consimilem monetam vel aliam in dicto Comitatu vel racione eius cudere vel cudi facere valeatis.

Reservábase el rey la reversión del condado en caso de que no hubiera sucesión hereditaria masculina legítima: Retinemus eciam nobis et nostris et sub hiis condicione modo et forma donacionem vobis facimus supradictam quod si vos vel filius seu filii aut nepotes vestri seu aliquibusque decedentes a vobis masculum sexus legittimi decedentis quod absit quocumque, absque filio vel filiis legitimis masculini sexus Comitatus predictus cum omnibus et singulis suprascripti, ad nos seu heredem nostrum et nostrorum qui pro tempore fuerint qui erit Rex aragonum libere et absque condiccione et impedimento quolibet integraliter devolvatur ac eciam revertatur.

El rey se comprometía por sí y sus sucesores a respetar las dotes de la esposa o esposas del infante y sus descendientes y, si la sucesión no era masculina, a colocar las hijas y nietas en adecuado matrimonio; en caso contrario el condado revertiría a la corona: Salvis tamen obligacionibus si quis ibi feceritis vos vel vestri, uxori vel uxoribus cum qua vel quibus duxeritis contraendum pro dotis et dotariis earumdem uxor quas et que uxoribus ipsis in dicto Comitatu salva esse volumus et illesa; si vero vos ac descendentes a vobis legitime masculini sexus sic descendentes relinqueritis filia vel filias, nepote vel nepotes nos vel heres noster universalis et sui teneamur et teneantur eas decenter iuxta condiciones earum matrimonio collocare, quo casu similiter comitatus predictis cum omnibus et singulis suprascriptis ad nos seu ad heredem nostrum et nostrorum predictum libere, et absque codicione et impedimento quolibet integraliter devolvatur ac eciam revertaur.

Añadía las disposiciones pro anima: Salvo eciam quod vos et vestri sic descendentes possitis ordinare pro anima vestra et vestris voluntatibus faciendis, usque ad quantitatem Mille Marcharum argenti quas nos vel heredes universalis noster et sui antequam dictum Comitatum recuperg. mus exsolvere teneamur et teneantur.

Igitur salvis et retentis nobis et nostris que superius continentur damus et cedimus vobis et vestris omnia iura nostra in premissis et singulis 
eorundem ac voces et acciones nobis pertinentes et pertinere debentes et contra quascumque personas et res racione eorum quibus possitis uti agere et operari in iudicio et extra quemadmodum nos fieri possumus autem huiusmodi donacionem.

La cláusula de constitución de propietario a favor del príncipe don Pedro y sus herederos era así: Constituentes vos et vestros in hiis omnibus et singulis, dominos et procuratores ut in rem vestram propriam sub formis et modis superius expressatis, iducentes eciam vos de presenti in corporalem possessionem omnium et singularum predictarum que vobis dicimus ad habendum tenendum possidendum in perpetuo a vobis et vestris predictis sucessoribus explectandum. Hanc autem donacionem et concessionem nostram facimus vobis, infanti Petro et vestris perpetuo sub forma predicta sicut melius et plenius ac sanius dici et intelligi potest ad vestrum et vestrorum salvamentum et bonum intellectum.

El rey mandaba por éste su privilegio a todos los vicegerentes, prelados, barones y demás constituidos en el dicho condado que lo observasen:

Mandantes per presens privilegium nostrum vicem eciam epistoli gerens, prelatis, baronibus, militibus, feudatariis, callaniis et universis et singulis aliis hominibus cuiuscumque legis et condicionis existant, infra dictum Comitatum constitutis, presentibus et futuris, quod vos memoratum infantem Petrum et vestros habeant pro dominis dicti Comitatus, et suis vobisque et vestris illis qui debuerint prestent et faciant homagium et fidelitate, prout sive pro feudis sive pro aliis eneantur et vobis pareant ac antendant ut Comiti ac domino dicti Comitatus, salvis tamen nobis et nostris de retencionibus predictis. Nos enim ipsos et eorum quelibet, ab omni homagio et obligacione quibus nobis teneantur absolvimus et propterea penitus liberamus.

Mandamus eciam universis officialibus et subditis nostris presentibus et futuris quod hanc donacionem et concessionem nostram teneant inviolabiliter et observent, et non contravenient nec aliquem contravenire permisant. El infante por su parte respondí: Ad hec nos Infans Petrus predictus confitentes sub virtute iuramenti inferius per nos presenti, Nos excessisse etate quatuordecim annorum et ultra recipientes cum reverencia et filiali subvencione a vobis excellentissimo principe et domino domino lacobo dei gracia Rege aragonum supradicto, domino et patre nostro karissimo iam emancipatus graciam donacionem et concessionem predictam, submodis formis condicionibus et retencionibus suprascriptis, ac eisdem omnibus et singulis prout superius largitus et clarius continentur consentientes expresse, convenimus et promittimus per nos et nostros vobis dicto domino Regi presenti et recipienti et vestris, modo formas condiciones et retenciones prescriptos, tam in prestando homagium quam in dandis potestate et potestatibus predictorum, ac aliis omnibus et singulis supra expressis, 
attendere et complere ac perpetuo per nos et nostros inviolabiliter observare.

Et hec omnia et sigula iuramus per deum et eius quator evangelia manibus nostris corporaliter tacta attendere et complere et in aliquo menquam contravenire.

Et eciam pro predictis et singulis facimus vobis de presenti homagium hore et manibus commendatum, iuxta usaticos barchinone et consuetudines Cathalonie. Ad huius autem rei memoriam et perpetuam firmitatem. facta sunt inde duo consimilia instrumenta, alterum habendum et tenendum per dictum dominum Regem, et alium per dictum infantem Petrum sigillata bulla plumbea dicti domini Regis et sigillo dicti domini infantis Petri. Quod est actum in Civitate llerde in ecclesia sedis eiusdem civitatis, die festi ascensionis dominice qua computabatur tercio decimo kalendas iunii anno domini $\mathrm{M}^{\circ} \mathrm{CCC}^{\circ}$ vicesimo secundo. Signum (la copia no lo reproduce) Iacobi dei gracia Regis Aragonum Valencie Sardinie et Corsice ac Comitis Barchinone qui premissa concedimus et firmamus. Sig + num Infantis Petri predicti qui predicta laudamus concedimus et firmamus.

Testes huius rei sunt qui presentes fuerunt Inclitus Infans Alfonsus domini Regis primogenitus et generalis procurator ac Comes Urgelli. Infans Raymundus Berengarius eiusdem domini Regis filius. Frater Martinus Petri de Oros, castellanus Emposte. Frater Arnaldus Guilelmi, abbas Monasterii de lauays, Bernardus de la Auellana, prior Monasterii Rotensi. Frater Berengarius de Erillo, prior de Ovarra. Raymundus Fulconis, vicecomes Cardone. Dalmacius vicecomes de rochabertino. Guillermus de montechathano senescallus Cathalonie. Exeminus de focibus. Raymundus Cornelii. Guillermus de angularia. Huguetus de Cardona filius nobilis Raymundi Fulconis quondam. Blasius maça de vergua. Raymundus de Peralta. Petrus de meytat. Petrus de sancto vincencio. Arnaldus de erillo. berengarius arnaldi de angularia. Guillelmus de queralto.

Et quamplures alii nobiles milites et alii in multitudine copiosa. Sig +num (no lo reproduce) mei bernardi de aversone dicti domini Regis notarï et publici eciam auctoritate sua per totam terram et dominacionem eiusdem qui predictis interfui et hec scribi feci et clausi loco die et anno prefixis.

La solemnidad del acto celebrado en la Seo de Lérida, cuya primera piedra se puso en 1203, bajo Pedro II de Aragón, podría evocarse ante la presencia del rey Jaime II, de su primogénito y heredero Alfonso, con el epíteto de Inclinus, de tradición goda, del creado, entonces, Pedro de Ribagorza, de su también hermano Ramón Berenguer, del castellán de Amposta, Martín Pérez de Oros; del abad de Lavaix, el monasterio que guardaba la documentación primitiva ripacurciense; de los vizcondes de Cardona y Rocabertí, del sensecal de Cataluña, de los señores de Peralta, Queralt y demás citados anteriormente. 
El infante era mayor de catorce años, como dice el acta de 20 de mayo de 1322, de creación del condado. Había nacido en 1305; de 1323 a 1325 fue procurador general de los reinos de la corona en ausencia de su hermano Alfonso IV de Aragón, quien volví́ a ocupar aquel cargo a su regreso de Cerdeña hasta ser coronado como rey en 1327 a la muerte de su padre Jaime II.

El infante residía ordinariamente en Valencia; su biografía puede resumirse así: nace en 1305, hijo de Jaime II y Blanca de Nápoles; en 1322, es conde de Ribagorza; en 1325, conde Ampurias; en 1331 casa con Juana, hija de Gastón de Foix; en 1354, al pasar a Cerdeña Pedro IV le confía todos sus estados. Viudo de Juana de Foix ingresa en 12 de noviembre en el convento de san Francisco de Barcelona; en 1367, se establece en Roma, con Urbano V; escribió De regimini Principum; murió en Pisa en 1381, el 4 de noviembre; sus restos fueron trasladados al convento de san Francisco de Valencia que desapareció por la amortización en el pasado siglo.

En 1325 Hugo de Cardona cedió el condado de Ampurias, del que se consideraba dueño, al infante don Pedro de Aragón que fue por ello conde de Ribagorza y de Ampurias. El infante don Pedro por convenio con el presunto heredero del condado de Ampurias, Hugo de Cardona, fallecido Malgaulí (1313-1322) con quien se extinguían los derechos soberanos, recibió dicho condado ampuritano cuyo título unió al de Ribagorza, convenido también con los hospitalarios que se creían con derechos a la herencia de Malgaulí.

El 14 de diciembre de 1319, Jaime II dio en Tarragona el privilegio de la unió dels regnes por el cual no podían separarse sus estados, Aragón, Valencia y el condado de Barcelona, y otros derechos que pudieran esperarse en el reino de Mallorca e islas adyacentes, Rosellón, Cerdaña, Conflent, Vallespir, Homelades y Carlades; aunque se reservó la facultad de hacer donación de lugares, castillos y heredamientos a sus hijos, nietos y demás personas que tuviere a bien. Es el privilegio CII del Aurem Opus, De unitate seu coniunctione regnorum Aragonum et Valencie et comitatus Barchinone (fol. LXIII).

Concedido al infante don Pedro el condado de Ribagorza, en la forma que se indica, don Pedro ejerció también como procurador general de los reinos de la Corona en ausencia del infante don Alfonso, su hermano, primogénito y heredero durante la estancia de éste en Cerdeña.

De 1325 a 1340 son las Ordinacions dels gremis de sabaters de Valencia; en 1327 bandositats, entre los Roiç y los Escorna; la ciudad actuaba de árbitro entre los señores, pues el rey no residía en ella; en 1328 Jaime II pelea contra el joven rey de Granada Ozmin Abduluyt que tenía Málaga; en el mismo año envía una embajada al rey de Bohemia. El 24 de octubre de 1329 se celebran cortes de Alfonso IV, II de Valencia ( 9 kalendas, noviembre). 
Entre 1316 y 1348 fue abad de Poblet don Ponce de Copons que antes de serlo había sido elegido en 1311 abad de Benifassá, donde construyó el aula capitular; fue abad de este monasterio entre 1316 y 1347 dom Bernard Pallarés, comisionado por el obispo de Valencia y delegado de Jaime II en la fundación de la Orden de Montesa.

El 24 de octubre de 1329 Alfonso IV de Aragón, II de Valencia, en 9 kalendas de aquel año se hallaba en Valencia para celebrar cortes ${ }^{6}$.

Entre 1329 y 1331, fue gobernador del reino de Valencia Jofre Gilabert de Cruilles; Alfonso IV le ordenó que le acompañase a Cerdeña para luchar contra los rebeldes y Génova; le sustituyó en aquella gobernación Pedro de Xérica quien la tuvo hasta 1335 en que por haberse indispuesto con el infante don Pedro, que era gobernador general de la Corona, fue exonerado ?

En 1336 fue dada posesión del castillo de Xátiva a la reina Leonor, viuda de Alfonso IV, que lo había reclamado (ACA Procesos, 511/18); en 1327 muere Jaime II: de 1327 a 1336 reinó Pedro IV el Ceremonioso; éste, en septiembre de 1336, dio en la catedral de Valencia el privilegio por el que no se enajenarían villas del reino.

En 1332 el infante don Pedro casó con Juana, hija de Gastón de Foix, la actuación del conde de Ribagorza iría a desarrollarse ya bajo el reinado de Pedro IV; de 1338 a 1339 era Justicia civil de Valencia Ramón dez Soler (ACA RP, núm. 2911); en 1342, Pero Martínez de Uncastelo, en Teruel (MR núm. 2394).

En 1344 fue la reincorporación de Mallorca; entre 1334 y 1347 tienen lugar luchas civiles en la ciudad de Valencia, entre Gilabert de Centelles y Dalmau de Cruilles, de Montesa; en 1354, Pedro IV confía al infante don Pedro todos sus estados, al pasar a Cerdeña.

En 1351 la ciudad tenía como propio ya el escudo real, cuatribarrado; en 1356 se ensanchó la antigua muralla de la ciudad; en 1359 en un Manual de Consells figuraban los dos escudos de la ciudad, el antiguo de la urbe sobre aguas, y el nuevo o escudo real, de los palos, con corona.

De 1348 a 1377 gobernaba Berenguela de Anglesola: los vasallos de la baronía de Vallbona fueron excluidos del trabajo de construir las murallas de Montblanch porque aquella baronía se defendía con el castillo de Olmells; en 1350 Blasco Hernández de Heredia tenía los castillos de Cetina y Ariza (MR núm. 2396).

6 a Anada dels reys a Valencia per tenir-hi Corts» HAR i LL. to, p. 7. Sobre la cláusula et juramentum pro ipsis servendis prestiterit non teneamini eum in regem vestrum aut dominum recipere nec sibi in aliquo respondere, que trae el Aurum Opus, fol. LXXXII, comentada por Eduardo de Hinojosa en Influencia que tuvieron en el Derecho público de su patria y singularmente en el Derecho penal los fitósofos y teólogos españoles anteriores a nuestro siglo (1890).

7 Josefina Mateu Ibars, Los Virreyes de Valencia, p. 78. 
En 1367 don Pedro, viudo de Juana de Foix, ingresó en 12 de noviembre en el convento de san Francisco de Barcelona; en 1377 la ciudad de Valencia usaba el escudo de los palos en rombo, a cayró, y la corona real; el Ceremonioso ordenó coronar la letra $\mathrm{L}$ del nombre tópico, Valencia.

En 1381 el infante don Pedro murió en Pisa; sus restos fueron trasladados a Valencia y enterrados en el convento de san Francisco; el edificio primero fue muy modesto; sufrió ruina, subviniendo a la erección de un nuevo templo Berenguer de Codinats, Maestre Racional de Pedro IV, que aún vivía en 20 de septiembre de 1382 en que eligí sepultura en el mismo convento. La lápida sepulcral de Berenguer de Codinats la vio Teixidor en 1767 , pero nada dice de la que tuviera el infante don Pedro al ser enterrado en la misma iglesia ${ }^{8}$, «En 14 agosto de 1361 Peregrin Guillem Catalá, como comprador de censos del conde de Ribagorza y Denia, don Alfonso de Aragón, extendí́ ápoca a favor de Manuel de Entenza y su mujer Castellana.»

\section{DON ALFONSO DE ARAGÓN Y FOIX}

Fallecido don Pedro en 1381, el condado pas 6 a don Alfonso de Aragón y Foix, marqués de Villena, conde de Denia, primer duque de Gandía, quien recibió este título por donación de Martín el Humano; es Alfonso llamado el Viejo quien intervino en la batalla de Nájera, donde fue apresado por los ingleses en 1367.

De aquel año es el Libre de la manifestació de tots los fochs del Comtat de Ribagorça, dels lochs propris del molt alt e poderos senyor don Alfonso, marqués de Villena, comte de Ribagorça e de Denia, feyt per lo honrat en Felip Boyl, batle general del dit Comtat de Ribagorça, ensemps ab mi notari davalscrit per via d'una comesio per lo dit senyor marques e comte feyta al dit batle general que dada fo en la vila de Gandia a XXV dies d'abril en l'any de la nativitat de nostre Senyor mill treentz huytanta e hun sigillada ab lo sigill de dit senyor en lo dors d'aquella ab cera vermeylla.

Josep Poch ha publicado documentos de Sacrae antiquitatis Cataloniae monumenta de 13 de juliol de 1337 (Biblioteca de Catalunya, ms. 729 , vol. VII, f. 316); referentes a un pleito entre un vecino de Benavarre y los hombres de dicha villa; otro de 136 (...) que contiene una carta de doña Violante, esposa de Alfonso y lugarteniente suyo en el Condado: Nos Vilant, del molt alt Senyor don Alfonso, Marqués de Villena, compre de

${ }^{8} \mathrm{M}$. Desamparados Cabanes Pecourt, Los monasterios valencianos, t. II, p. 10, reproducción de un antiguo grabado que muestra el templo en la época que vivió Teixidor y se mantuvo hasta el pasado siglo XIX en que fue derribado; la interpretación del antiguo grabado es de 1952, por Eutimio Fernández. 
Ribagorç et de Denia muller et general lochtinent, en que refiere como les companyes de França que son entrades en Principat de Cauthafunya, fo es per les partides de Payllars, y como ella con sus hijos habianse ido al castell nostre Pera-Rua y que els feells nostres prohomes del lloch de capella les habían prestado para la provisión deu cafiz de forment e sis lits de roba per a nostres companyes y considerando además que los prohombres le habían dado graciosamente ciento cincuenta sueldos.

Después, en 23 de enero de 1370, la misma señora Condesa de Ribagorģa, atenen que per la reempşo o rescat del molt alt Senyor don Alfons, marques, car senyor et marit nostre, había recibido 6.000 sueldos jaqueses de les universitats del lochs de Benavarre, Capella, Tolva, Estopanyà ef Azanuy y que habían vendido tres mil sueldos censales a Berenguer de Almenar, otorgaba a los prohombres de Capella estuvieran en su fuerza los privilegios, usos y libertades como antes de la venta del censal.

El primer censo de 1381 consta de cinco folios: Libre de la manifestació de tots los fochs del Comdat de Ribagorça, fet per Felip Boyl, balle general del dit Comdat, publicado por José Camarena Mahiques, en 1966. quien dice que el texto fue redactado por Pedro Sayo, notario, vecino de Tolva que acompañó al baile en la formación del censo.

La plaza de Nájera tuvo un papel trascendente en la vida del conde de Ribagorza don Alfonso de Aragón y Foix: en 1360 en la guerra entre Pedro I de Castilla y Pedro IV de Aragón, los hermanos bastardos de aquél, don Enrique de Trastámara y don Tello se apoderaron de la ciudad, pero don Pedro I se adueñó de Miranda de Ebro y derrotó a don Enrique ante Nájera, desde la cual éste marchó a Aragón. Siete años después, en 1367, las compañías inglesas del Príncipe Negro, llevando consigo a don Pedro, desde Logroño atacaron al de Trastámara; «los castellanos formaban un gran cuerpo de batalla. Entre elíos estaba Beltrán Duguesclin. El ala izquierda la mandaba don Tello y el ala derecha el marqués de Villena» (Diccionario de Historia de España, 3, p.1).

Alfonso de Aragón era hijo del infante don Pedro, el conde de Ribagorza, y Juana de Foix, y en él recayó también el condado de Denia: en 1399 fue nombrado duque de Gandía; Enrique de Trastámara le dio el marquesado de Villena que era de Castilla, y Juan I le nombró condestable de Castilla en 1382; fue tutor del que sería Enrique III (1390-1406) y aspiro a la Corona de Aragón al morir Martín el Humano (1410); cas6 con Violante de Arenós, en 1352, de quien nacieron: Jaime, conde de Ribagorza; Alfonso, que le sucedió en sus estados; y Pedro que fue marqués de Villena casó en segundas nupcias con María de Navarra, hija de Carlos II el Malo (13491387) de quien no hubo sucesión.

El segundo censo es el del Libre dels morabetins manifestats por los prohomens dels lochs del Comtat de Ribagorf̧a aixi del senyor marques com dels lochs de les ordens poblats dins lo dit Comtat, exceptat dels lochs 
de Sent Victoria, qui es lo morabati del abat de Sent Victoria per concessio real e del loch de Arasan qui es del abat de Levaix que null temps se paga. La qual manifestacio fonch feta en poder de mi Berenguer Campredon batle general del dit Comtat.

La moneda del censo de 1381 era de sous barchinonesos; por la cuantía dels valors de sus bienes se agrupaban los moradores asi: primerament valents III mill sous barchinonesos, luego los de II mil, los de mil y finalmente los pobres e dones vidues miserables. Los lugares censados fueron: Benavarre, Elins, Açanuy, Espluga de Sant Quiliu, Stopanya, Entença, Tolba e Falçs, Viacamp e Litera, Loças, Castigaleff, Monesma, Castelsent, Montanyana, Cornudela, Arenyn, Valdecires e honor de Iscles, Bonansa, Elins e Les Pahuls, Castanesa, Benasch e les aldees, Sahu, Eresuy, Gavas, Liry, Castello de Sos. Sors, Bery, Val de Lirp, Val de Taraça, Sadaruy, Balabriga, Sent Esteve del Mayl, Lascuarre, Laguares, Guell, Santalestra, Erdaho, Fonthova, Capella, Paniello, Jeraruha, Juseu y Calasanç, respetando aquí su ortografía.

El morabatí de 1385 en más lugares que los registrados en los fochs de 1381 quitándose La Spluga de sent Quilez que es del senyor marques e Çoriana, del monastir de Poble, foren atrobats morabatins clas en la dita Spluga IIII e en Coriana, V: Otras localidades són: Suert, La Torre de Buyra, del abat de Lavis, Sent Lorenç, Iscles form, Buyra, Cires, Gavarret del denyot Marques Sent Oerde de Molins de el abat d'Alaho, a edición de José Camarena Mahiques, trae índices de apellidos, de los moradores y de lugares.

De 1405 a 1409 era virrey de Valencia, don Alfonso de Aragón, conde de Denia y de Ribagorza, nombrado por Martín el Humano; era hijo del duque de Gandía y bisnieto de Jaime II.

Un documento de 8 de septiembre de 1413 de Sacrae antiquinatis Cataloniae Monumenta (vol. VII, f. 217) publicado también por Josep Poch, dice asi: Nos don Alfonso, duch de Gandia, comte de Ribagorşa et de Denia, a humil supplicacio a nos feta por los amats nostres los batles, jurats, prohomens et consell de la vila de Benavarre situada en lo comtat nostre de Ribagorça, les permitía construir un monestir del Orde de frares preycadors en la devota appelleda Santa Maria de Linars, con todo lo necesario, limosnas, donaciones $y$ herencias.

A don Alfonso de Aragón y Foix, llamado el Viejo, o primer duque de Gandía y conde de Ribagorza, sucedióle su hijo Alfonso de Aragón, el Joven, también conde de Ribagorza, que murió en 31 de agosto de 1422.

En 1433 como lugarteniente de su hermano Alfonso el Magnánimo, Juan II extendía un documento con esta intitulación: Nos Johannes Dei gracia Rex Navarre, Infans Aragoum et Sicilie, Dux Nemorensis, Gandie, Montisalbi et Petrefidelis, Comes Ripacurcie ac Dominus Civitatis Balagarii necnon Illustrissimi Principis Domini Alfonsi eadem gracia Regis 
Aragonum et Sicilie, fratris nostri carissimi in Regnis Aragonum et Valencie Locumtenens. Juan II ostentaba, pues, este título condal siendo Infante y pro rex; una medalla lo recuerda: Johannes de Aragonia Ripacurcie Comes, Cataloniae Prorex, obedeciendo a los aires renacentistas de aquellos tiempos.

En las actas de abril de 1441 a junio de 1446 del Consell general del Comtat de Ribagorça, adunat a Benavarre, durant el govern de l'Infant Joan, de la Real Academia de la Historia, Colección Salazar y Castro (ms. V. 37. fol, 322) publicado por el P. Josep Poch en la citada Revista Catalunya (1980, núm. 222) donde da la pertinente bibliografia, consta Juan II, rey de Navarra, rogaba a los prohombres de Benavarre que le enviasen diez ballesteros armats e be a punt e homens fiables, pagados por tres meses. La intitulación y dirección diplomática eran así: Als amats e feels nostres los lochtinent de procurador e Jurats e prohomens del Consell General del Comtat de Ribagorça, lo Rey de Navarra, Infant e Governador General de Aragó e de Sicilia.

Entre 1390 y 1406, reinó en Castilla Enrique III; su hija María casó con Alfonso el Magnánimo (1416-1458) hermano de Juan II, quien había sido Infante gobernador y rey de Navarra (1438-1458).

\section{RIBAGORZA Y VILLAHERMOSA}

El ducado de Villahermosa fue creado por Juan II de Aragón en 1476 para don Alfonso de Aragón, hijo natural suyo, conde de Ribagorza y conde y señor de Cortes, XXVII maestre de la orden de Calatrava.

Una provisión del virrey de Cataluña en 1499 dice así: Nos Don Joan Darago compte de Ribagorça Lochtinent general del Serenissimo Senyor Rey nostre observantissim en los Principat de Cathalunya e Comtats de Rosello e de Cerdanya, sobre el bon ordre y stament, concedió el privilegio de la insaculación, dada en la Ciutat de Leyda de set dies del mes de maig en l-any de la nativitat de Nostre Senyor mil quatrecents noranta nou, del Regne de Sicilia l-any 32, de Castella e de Leo vint e sis, de Arago e dels altres vint e hu e de Granada l-any vuyte, El Conde lugarteniente general.

En 1645 el Dr. don Francisco Ximenes de Urrea, capellán de SM y cronista del Reino de Aragón refería que en Longares habíase descubierto dos mil monedas ibéricas (las llamaba «de hombre encima del caballo con una lanza») según papeles de don Martín de Aragon, duque de Villahermosa y conde de Ribagorza, la relevante figura de los tiempos de Vincencio Juan de Lastanosa. 
En 1818 el Dr. don Josef Salat dedicó su Tratado de las monedas labradas en el Principado de Cataluña, al Duque de Medinaceli, Feria, Segorbe y Cardona, Marqués de Denia y de Pallars.

En 1905 doña María del Carmen Aragón Azlor, Duquesa de Villahermosa, erigí en Petrola un mausoleo dedicado a su antepasada, Aloisa de Borja Comitissa Ripacurciae Ducisa Vilahermosae, esposa del Duque de Villahermosa, don Martín de Gurrea y Aragón que acompañó a Felipe II a Inglaterra, según consta en la medalla acuñada en aquel año, 1904, en la que se reproduce la efigie de aquélla y el mausoleo con la estatua orante de la misma. 